\title{
Treatment delay among smear positive pulmonary tuberculosis patients in south Ethiopia: A cross-sectional study
}

\author{
Zerihun Zerdo Zeleke ${ }^{1, *}$, Zemedu Mehamed Trifa ${ }^{2}$ \\ ${ }^{1}$ Department of Medical Laboratory Science, College of Medicine and Health Science, Arbaminch University, Arbaminch, Ethiopia \\ ${ }^{2}$ Department of public health, College of Medicine and Health Science, Arbaminch University, Arbaminch, Ethiopia
}

\section{Email addresses:}

zedozerihun@gmail.com (Z.ZZerdo),zemedumohamed@yahoo.com (Z. Mohammed)

\section{To cite this article:}

Zerihun Zerdo Zeleke, Zemedu Mehamed Trifa. Treatment Delay among Smear Positive Pulmonary Tuberculosis Patients in South Ethiopia: A Cross-Sectional Study. Science Journal of Public Health. Vol. 2, No. 5, 2014, pp. 402-409.

doi: $10.11648 /$ j.sjph.20140205.15

\begin{abstract}
Background: Most tuberculosis (TB) patients were not visiting heath facility but transmit disease to healthy individuals in the community for longer time in Ethiopia. This study was aimed at estimating duration of delay for initiation of anti-TB treatment by smear positive pulmonary TB in south Ethiopia and assesses its determinants of patient related factors associated with unacceptable delay for medication of TB. Methods: a cross-sectional study design was used to recruit 218 consecutive smear positive pulmonary TB patients visiting there hospitals in Gamo Goffa Zone. A structured questionnaire was used to collect information on socio demographic, economic, behavioral factors and co morbidity with HIV from the study units. The median delay was used as cut-off point to dichotomize acceptable delay from unacceptable one. Pearson chi square and logistic regressions were used to assess association between patient factors and longer delay before treatment. Results: The median delay for initiation of anti-TB medication by smear positive pulmonary TB patients was 35 days. Fifteen of the study participants were HIV positive and equal number of TB patients involved had previous history of TB. Socio-demographic factors significantly associated with longer delay for treatment of TB in Univariate analysis were place of residence, level of education and marital status while economic factors associated were monthly income, whether the house is owned or rented and ceiling status of the house. However, after controlling the effect of confounding variables only place of residence and monthly income remained statistically significant. TB patients from rural area were 2.82 times at increased risk to delay for longer days than those living in the town ( $p$-value $=0.021$ ). Similarly, patients having monthly income of 450 or less Ethiopian birr were 4.96 times more likely to delay for longer time than those who had no regular monthly income ( $\mathrm{p}$-value=0.003). Conclusion: Smear positive pulmonary TB patients delay for more days before taking anti-TB medications which renders them noninfectious after a few weeks of treatment began. They were transmitting the disease in the community making prevention and control more difficult. Those living in the rural area and earn least amount of money per month transmit the disease for longer time. Civil servants who earn the least salary per month had significant increment in the salary recently that might prevent their delay. However, access to diagnosis and treatment of TB for people living in the rural area should be improved so as to help the walk towards the millennium development goal targets.
\end{abstract}

Keywords: Treatment Delay, Smear Positive Pulmonary TB, South Ethiopia

\section{Introduction}

Tuberculosis (TB) is one of the major health challenges in the world [1]. It is bacterial disease transmitted from an infectious patient; smear positive pulmonary TB, to the other susceptible individuals through air droplets. An infectious patient can infect 10-15 individuals per year [2]. Fortunately, only $5-10 \%$ of the infected individuals develop active TB. The burden of TB is high in developing countries like Ethiopia [2, 3]. Ethiopia ranks the $8^{\text {th }}$ among 22 TB-high 
burden countries with an estimated incidence and death of 230, 000 TB cases of all forms and 16000 deaths excluding deaths among HIV positive TB patients respectively. Tremendous effort has been made to control TB since it was declared as an emerging health problem $[1,2]$.

Early case identification and prompt treatment of the infectious cases was used as the major mechanism to prevent and control TB. WHO Launched directly observed treatment short-course (DOTS), patients take anti-TB drugs under the supervision of health care providers, as the main strategy of TB control in the mid of 1900. Ethiopia has adopted DOTS strategy as a pilot in Aris and Bale Zones of Oromia region in 1992. Currently, the geographical coverage of DOTS reached $100 \%$ while the health facility coverage is $95 \%[4,5]$. Nevertheless, the case detection rate of TB lags behind the 2015 target of $70 \%$ or more. Thus, Ethiopia was among countries which are off track to reach the millennium development goal with respect to the case detection rate. The national case detection rate in Ethiopia was $64 \%$ in 2012 , decreased by $4 \%$ as compared to the case detection rate in 2011 [1]. Delayed diagnosis and treatment might be among the factors related to low case detection rate in Ethiopia in general and south Ethiopia in particular.

Delayed diagnosis and initiation of anti-TB treatment increases suffering of the patient and the chance of transmission of the disease in the community. Both the health system and patient contribute to delayed diagnosis and treatment of TB. Two previous studies conducted in Ethiopia indicate that the median total delay was 70.5 days in Afar regional state and 97 days in Bale Zone in Oromia regional state $[6,7]$. The highest delay (357 days) observed as to the knowledge of the authors were considered was in Afghanistan [8]. These and other related studies conducted in different geographical locations in the glob have assessed factors favoring delayed diagnosis and treatment of TB.

One of the most common factors increasing delay for diagnosis and treatment of TB was type and place where the health service was. Increased distance requires additional cost for transportation which hinders the patient to visit health facility as early as possible [6-13]. As it is known as the most important risk factor for TB, smoking cigarette also increases the delay for diagnosis and treatment as compared to non-smokers and ex-smokers [14]. The other factors increasing delay for treatment were variables in the socio demographic $[6,11,13,15-17]$, economic [10-12], concurrent chronic diseases [11, 18] and knowledge about TB [10, 11, 19]. These findings indicate that variables affecting the prompt treatment of TB vary according to geographical location and population, calling for studies intended to estimate and identify area and population specific factors associated with increased delay of the patients for treatment. Delayed diagnosis of pulmonary TB is also associated with drug resistance as indicated in one study conducted in South Africa [20]. Therefore, in the present study we have estimated the total delay defined as time from onset of TB symptoms, cough being the most prominent, to initiation of anti-TB treatment among smear-positive pulmonary TB patient in South Ethiopia. Furthermore, we have assessed patient related factors favoring increased delay for treatment.

\section{Methodology}

\subsection{Study Area and Population}

This study was undertaken in three hospitals found in Southern Ethiopia namely; Arba Minch, Sawula and Chencha Hospitals. These hospitals are located in Gamo Goffa Zone. Gamo Goffa Zone is constituted of 15 districts and two town administrations. Projection of 2007 population size of Gamo Goffa Zone for about five years with growth rate of $2.7 \%$ indicates that a total of $1,820,105$ population live in the study area in 2012 . About $50.2 \%$ of the total population was women [21]. However, patients from surrounding Zones (second largest administrative unit next to regional state in Ethiopia) and special districts get health care service from these hospitals.

\subsection{Study Design and Selection of Study Participants}

A cross-sectional study design was used to enroll 221 consecutive smear-positive pulmonary TB patients visiting three hospitals from March 2013 to February 2014. Only adults aged $\geq 18$ years and consented to participate, mentally fit and whose HIV status was known were involved as study units in the present research. Accordingly, 131 from Arba Minch, 47 from Sawula and 43 from chencha hospital were included in the study. Nevertheless, for three of TB patients the data was incomplete and they were excluded from the analysis.

\subsection{Definition of Terms}

Sputum-smear positive: two or more of the three sputum smear were positive for acid fast bacilli in light microscopy or one sputum smear positive and either chest $\mathrm{X}$ ray (CXR) investigations are consistent with active TB or the patient is HIV positive.

Delay for initiation of anti-TB treatment: is the time interval between onsets of TB symptoms, cough being the prominent, to initiation of anti-TB treatment.

\subsection{Procedure of Data Collection}

A structured questionnaire was used to collect data on socio demographic, behavioral and economic factors from the patients. The questionnaire was prepared in English and translated into local languages and then back translated to English to check accuracy. It was used to interview study units by health care providers by the appropriate colloquial language in the three hospitals. Information on the HIV status of the participant was obtained from the patient registration book. A face to face interview was used to collect data from the study participant by the health worker 
in the TB clinic for confidential purpose.

\subsection{Statistical Analysis}

All collected data were checked before computerizing using EpiData version 3.1 software. After exporting the data into STATA version 11, results from frequencies and cross-tabulations were used to monitor transcription errors. Different scholars use various methods to classify delay as acceptable or not. Some use certain number days as the acceptable $[7,22,23]$ while others use central tendency as cut-off point $[6,24]$. Similar to previous study conducted in Afar regional state in Ethiopia, we have used the median as cut-off point. Wilcoxon signed-rank test was used to determine whether the estimated delay was significantly different from similar studies or not. Chi square and fisher's exact test were used to identify factors associated with delay for initiation of anti-TB treatment among smearpositive pulmonary TB patients. Odds ratio from Univariate logistic regression was used to quantify the association before adjusting for potential confounding variables. Variables significantly associated in Pearson's chi square and fisher's exact test, used appropriately, were included in multivariable logistic regression to adjust effect of potential confounding variables. Odds ratio (OR) and corresponding $95 \%$ confidence intervals $(\mathrm{CI})$ were used to quantify the degrees of association between target potential risk factor and delay. Results with p-value less than 0.05 were considered as being statistically significant.

\subsection{Ethical Considerations}

The study protocol was approved by research ethics review committee of college of medicine and health science in Arba Minch university before commencement of the study (Reference number of the approval letter: IRC/003/05). Permission to conduct the research was obtained from health department of Gamo Goffa Zone, each hospital authorities after giving them recommendation letter written by Arba Minch University. Finally written informed consent was obtained from the study participant before retrieving data and interviewing.

\section{Results}

A total of 221 smear positive pulmonary TB patients were registered for treatment in the TB clinic of the three hospitals from March, 2013 to February, 2014. For 98.6\% (218/221) of the registered TB patients data was complete with respect to delay and were involved in the present study. Majority of the patients were from Arba Minch hospital which is located in the administrative center of the Zone. Just above $64 \%$ were male, $64.7 \%$ were living in rural area; $43 \%$ were married; one-fourth was unable to read and write. The age of the patients involved in the study was skewed to the right with the median age of 28 years. Just above $92 \%$
$(203 / 220)$ of the study participants were in the economically most active age group of less than 54 years. The detailed background characteristic of the study population was depicted in table1.

The duration of treatment between TB symptoms were observed to taking medication was skewed to the right with the median delay of 35 days. In univariable logistic regression, residence in rural area, who had no formal education, history of marriage (not living together or divorced for any reason) were significantly associated risk factors of unacceptable delay for initiation of ant-TB treatment. Even though the association is not significant enough, drinking alcohol also increases the likelihood of delay for medication of the patients. However, after controlling the effect of confounding variables only place of residence remained statistically significant (table3). TB patients living in the rural area of south Ethiopia were about 2.8 times more likely to delay than those living in the town. HIV infection status, previous history of TB and some socio economic factors were considered in this study.

With respect to economic factors, almost all patients registered (217/218) had home: either owned or rented. One hundred and one smear positive pulmonary $\mathrm{TB}$ patients were living in his/her own home but such patients had more chance to delay for longer time before seeking for medication than those rented once in Univariate analysis. However only $35.75 \%$ of these houses had ceiling and $23 \%$ of the houses floor was cemented. Patients from ceiled house were 0.5 ( $p$ value $=0.019$ ) times less likely to delay than patients owning or rented a house its roof is not ceiled. The mean household size, eating from the same pot, was 5.3 individuals with the maximum above 100 and that was from prison. Patients from a household size of more than five increases the delay for seeking medication of TB. Those from high number of household were 1.73 times more likely to delay for longer time than patients from house hold size less than or equal to 5 but it is not statistically significant The floor of 166 houses was cemented and the rest were either soil or other forms. About 25 study participants had monthly income of Ethiopian birr 450 or less while 124 had no regular income per month. However, those who earn less than 450 birr were about 4.96 times at increased risk to delay for more time before treated for TB (table 3 )

When the background health status of the participants was concerned, $6.9 \%$ were HIV positive and $6.88(15 / 218)$ were retreatment patients. Being HIV infected and previously treated for $\mathrm{TB}$ had protective effect on the unacceptable delay for medication of TB than HIV negative and those who had no history of TB disease in Univariate analysis. HIV negative and new TB patients were 1.3 (pvalue $=0.651)$ and $(p$-value $=0.637)$ times more likely to delay for unacceptably longer time than HIV positive and retreatment cases respectively (table 2). 
Table 1. Socio-demographic characteristics of smear positive pulmonary TB in south Ethiopia, 2013-2014

\begin{tabular}{|c|c|c|c|}
\hline Characteristics & Categories of characteristics & Number (\%) & fDelayed initiation of treatment $(\%)$ \\
\hline \multirow{2}{*}{ sex } & Female & $79(35.91)$ & $40(50.63)$ \\
\hline & Male & $141(64.09)$ & $59(42.75)$ \\
\hline \multirow{4}{*}{ Age in years } & $\leq 24$ & $76(34.55)$ & $28(37.33)$ \\
\hline & $25-34$ & $77(35.00)$ & $36(46.75)$ \\
\hline & $35-44$ & $35(15.91)$ & $21(63.64)$ \\
\hline & $\geq 45$ & $32(14.55)$ & $14(43.75)$ \\
\hline \multirow{3}{*}{ Marital status } & Single & $95(42.99)$ & $35(36.84)$ \\
\hline & Married & $113(51.13)$ & $57(50.44)$ \\
\hline & Others & $13(5.88)$ & $8(80.00)$ \\
\hline \multirow{3}{*}{ Level of education } & no formal education & $70(31.67)$ & $42(60.87)$ \\
\hline & Primary (grade 1-8) & $80(36.20)$ & $33(41.77)$ \\
\hline & $\geq$ high school & $71(32.13)$ & $25(35.71)$ \\
\hline \multirow{6}{*}{ Occupational status } & Civil servant & $15(6.82)$ & $4(28.57)$ \\
\hline & Farmer & $82(37.27)$ & $42(51.22)$ \\
\hline & Merchant & $18(8.18)$ & $7(41.19)$ \\
\hline & Housewife & $39(17.73)$ & $19(50)$ \\
\hline & Student & $49(22.27)$ & $16(32.65)$ \\
\hline & Others & $17(7.73)$ & $12(70.59)$ \\
\hline \multirow{4}{*}{ Monthly income(ETB) } & No regular income & $124(56.11)$ & $56(45.53)$ \\
\hline & $1-450$ ЕTВ & $25(11.31)$ & $19(76.00)$ \\
\hline & 451-1000 ЕТВ & $43(19.46)$ & $17(39.53)$ \\
\hline & $\geq 1001 \mathrm{ETB}$ & $29(13.12)$ & $8(29.63)$ \\
\hline \multirow{2}{*}{ Place of residence } & Rural & $143(64.71)$ & $77(54.61)$ \\
\hline & Urban & $78(35.29)$ & $23(29.87)$ \\
\hline \multirow{2}{*}{ Ever smoke cigarette } & Yes & $21(9.5)$ & $11(52.38)$ \\
\hline & No & $200(90.5)$ & $89(45.18)$ \\
\hline \multirow{2}{*}{ Ever drunk alcohol } & Yes & $79(35.75)$ & $29(37.18)$ \\
\hline & No & $142(64.25)$ & $71(50.71)$ \\
\hline \multirow{2}{*}{ HIV infected } & Yes & $15(6.82)$ & $6(40.00)$ \\
\hline & No & 205(93.18) & $93(46.05)$ \\
\hline \multirow{2}{*}{ History of anti-TB treatment } & Yes & $15(6.79)$ & $6(40.00)$ \\
\hline & No & $206(93.21)$ & $94(46.31)$ \\
\hline
\end{tabular}

Table 2. Associations of socio-demographic and economic factors of smear positive pulmonary TB and unacceptable delay for initiation of TB medication in south Ethiopia, 2013-2014

\begin{tabular}{|c|c|c|c|c|c|}
\hline \multirow{2}{*}{ variable } & \multirow{2}{*}{ Category of variable } & \multicolumn{2}{|c|}{ Unacceptable delay (greater than median delay) } & \multirow{2}{*}{ Pearson $\chi^{2}$} & \multirow{2}{*}{ p-value } \\
\hline & & Yes $(\%)$ & No $(\%)$ & & \\
\hline \multirow{2}{*}{ Sex } & Female & $40(50.63)$ & $39(49.37)$ & \multirow{2}{*}{1.26} & \multirow{2}{*}{0.262} \\
\hline & Male & $59(42.75)$ & $79(57.25)$ & & \\
\hline \multirow{4}{*}{ Age in years } & $\leq 24$ & $28(37.33)$ & $47(62.67)$ & \multirow{4}{*}{6.48} & \multirow{4}{*}{0.091} \\
\hline & $25-34$ & $36(46.75)$ & $41(53.25)$ & & \\
\hline & $35-44$ & $21(63.64)$ & $12(36.36)$ & & \\
\hline & $\geq 45$ & $14(43.75)$ & $18(56.25)$ & & \\
\hline \multirow{3}{*}{ Marital status } & Single & $35(36.84)$ & $60(63.16)$ & \multirow{3}{*}{8.76} & \multirow{3}{*}{$0.012 *$} \\
\hline & Married & $57(50.44)$ & $56(49.56)$ & & \\
\hline & Others & $8(80.00)$ & $2(20.00)$ & & \\
\hline \multirow{3}{*}{ Level of education } & no formal education & $42(60.87)$ & $27(39.13)$ & \multirow{3}{*}{9.69} & \multirow{3}{*}{0.008} \\
\hline & Primary (grade 1-8) & $33(41.77)$ & $46(58.23)$ & & \\
\hline & $\geq$ high school & $25(35.71)$ & $45(64.29)$ & & \\
\hline \multirow{6}{*}{ Occupational status } & Civil servant & $4(28.57)$ & $10(71.43)$ & \multirow{6}{*}{10.66} & \multirow{6}{*}{0.058} \\
\hline & Farmer & $42(51.22)$ & $40(48.78)$ & & \\
\hline & Merchant & $7(41.19)$ & $10(58.82)$ & & \\
\hline & Housewife & $19(50)$ & $19(50.00)$ & & \\
\hline & Student & $16(32.65)$ & $33(67.35)$ & & \\
\hline & Others & $12(70.59)$ & $5(29.41)$ & & \\
\hline \multirow{2}{*}{ Monthly income(ETB) } & No regular income & $56(45.53)$ & $67(54.47)$ & \multirow{2}{*}{12.71} & \multirow{2}{*}{0.005} \\
\hline & 1-450 ЕТВ & $19(76.00)$ & $6(24.00)$ & & \\
\hline
\end{tabular}




\begin{tabular}{|c|c|c|c|c|c|}
\hline \multirow{4}{*}{ variable } & \multirow{2}{*}{ Category of variable } & \multicolumn{2}{|c|}{ Unacceptable delay (greater than median delay) } & \multirow{2}{*}{ Pearson $\chi^{2}$} & \multirow{2}{*}{ p-value } \\
\hline & & Yes $(\%)$ & No (\%) & & \\
\hline & 451-1000 ETB & $17(39.53)$ & $26(60.47)$ & & \\
\hline & $\geq 1001 \mathrm{ETB}$ & $8(29.63)$ & $19(70.37)$ & & \\
\hline \multirow{2}{*}{ Place of residence } & Rural & $77(54.61)$ & $64(45.39)$ & \multirow{2}{*}{12.28} & \multirow{2}{*}{0.000} \\
\hline & Urban & $23(29.87)$ & $54(70.13)$ & & \\
\hline \multirow{2}{*}{ Ever smoke cigarette } & Yes & $11(52.38)$ & $10(47.62)$ & \multirow{2}{*}{0.40} & \multirow{2}{*}{0.529} \\
\hline & No & $89(45.18)$ & $108(54.82)$ & & \\
\hline \multirow{2}{*}{ Ever drunk alcohol } & Yes & $29(37.18)$ & $49(62.82)$ & \multirow{2}{*}{3.60} & \multirow{2}{*}{0.055} \\
\hline & No & $71(50.71)$ & $69(49.29)$ & & \\
\hline \multirow{2}{*}{ HIV infected } & Yes & $6(40.00)$ & $9(60.00)$ & \multirow{2}{*}{0.21} & \multirow{2}{*}{0.650} \\
\hline & No & $93(46.05)$ & $109(53.96)$ & & \\
\hline \multirow{2}{*}{ History of anti-TB treatment } & Yes & $6(40.00)$ & $9(60.00)$ & \multirow{2}{*}{0.22} & \multirow{2}{*}{0.636} \\
\hline & No & $94(46.31)$ & $109(53.69)$ & & \\
\hline
\end{tabular}

Table 3. Predictors of unacceptable delay for initiation of ant-TB treatment among smear positive pulmonary TB in south Ethiopia, 2013-2014

\begin{tabular}{|c|c|c|c|c|c|}
\hline \multirow{2}{*}{ variable } & \multicolumn{2}{|c|}{ Unacceptable patient delay } & \multirow{2}{*}{$\begin{array}{l}\text { Crude OR } \\
(95 \% \text { CI) }\end{array}$} & \multirow{2}{*}{$\begin{array}{l}\text { Adjusted OR } \\
(95 \% \text { CI) }\end{array}$} & \multirow{2}{*}{ p-value } \\
\hline & Yes (\%) & No (\%) & & & \\
\hline \multicolumn{6}{|l|}{ Place of residence } \\
\hline rural & $77(54.61)$ & $64(45.39)$ & $2.82(1.57-5.10)$ & $3.49(1.20-10.10)$ & \multirow{2}{*}{0.021} \\
\hline urban & $23(29.87)$ & $54(70.13)$ & 1 & 1 & \\
\hline \multicolumn{6}{|l|}{ Marital status } \\
\hline Single & $35(36.84)$ & $60(63.16)$ & 1 & 1 & \\
\hline married & $57(50.44)$ & $56(49.56)$ & $1.74(1.00-3.04)$ & $1.19(0.58-2.44)$ & 0.633 \\
\hline Others & $8(80.00)$ & $2(20.00)$ & $6.86(1.39-34.12)$ & $5.12(0.91-28.73)$ & 0.064 \\
\hline \multicolumn{6}{|l|}{ Level of education } \\
\hline no formal education & $42(60.87)$ & $27(39.13)$ & 1 & 1 & \\
\hline Primary (grade 1-8) & $33(41.77)$ & $46(58.23)$ & $0.46(0.24-0.89)$ & $0.62(.29-1.30)$ & 0.204 \\
\hline$\geq$ high school & $25(35.71)$ & $45(64.29)$ & $0.36(0.18-0.71)$ & $1.01(0.33-33.13)$ & 0.963 \\
\hline \multicolumn{6}{|c|}{ Monthly income in Ethiopian birr (ETB) } \\
\hline No regular income & $56(45.53)$ & $67(54.47)$ & 1 & 1 & \\
\hline $1-450$ ЕTВ & $19(76.00)$ & $6(24.00)$ & $3.79(1.42-10.14)$ & $4.96(1.71-14.35)$ & 0.003 \\
\hline 451-1000 ЕТВ & $17(39.53)$ & $26(60.47)$ & $0.78(0.39-1.59)$ & $0.90(0.42-1.90)$ & 0.781 \\
\hline$\geq 1001$ ETB & $8(29.63)$ & $19(70.37)$ & $0.50(0.21-1.24)$ & $0.96(0.32-2.86)$ & 0.940 \\
\hline \multicolumn{6}{|c|}{ House where patient living } \\
\hline Rented & $11(29.73)$ & $26(70.27)$ & 1 & 1 & \multirow{2}{*}{0.638} \\
\hline Owner & $89(49.17)$ & $92(50.83)$ & $2.29(1.07-4.90)$ & $1.27(0.47-3.43)$ & \\
\hline \multicolumn{6}{|c|}{ Roof of the participant's house } \\
\hline Not ceiled & $73(51.77)$ & $68(48.23)$ & $1.99(1.12-3.53)$ & $1.46(0.57-3.69)$ & \multirow{2}{*}{0.429} \\
\hline ceiled & $27(35.06)$ & $50(64.94)$ & 1 & 1 & \\
\hline
\end{tabular}

\section{Discussion}

Unacceptably longer duration between the onset of TB symptoms and taking treatment of infectious TB patients was high in South Ethiopia. They transmit the disease to the general community and their families making TB prevention and control more difficult. Patients living in the rural part of the study area and who earn 450 or less Ethiopian birr per month delay for significantly longer time before taking anti-TB treatment. In contrast, HIV infection and previous history of treatment for $\mathrm{TB}$ had protective effect on delay for more than 35 days of seeking medication by the patient though it was not statistically significant.

The median delay for initiation of treatment after recognizing TB symptoms was 35 days. This delay was significantly lower than the previous studies conducted in the Afar and Oromia regions in Ethiopia [6, 7]. The possible reason for this difference will be on the study participants involved. Majority of the study participants in the previous two studies in Ethiopia were pastoralists. Pastoralists delay for unacceptably longer time between the onsets of the symptom and seeking medical care as indicated on these studies. Unlike these studies, almost all TB patients in the present study were not pastoralists. Except a study conducted in migrant population in china [25], the delay estimated in this study was lower as compared to other inquiries carried out in Africa and some other countries.

Four previous studies conducted in African region were reviewed. The median total delay of TB patients before taking TB treatment was lower in the present study than in Malawi [26], Nigeria [13] Uganda [19] and Mozambique [18]. As indicated in the national TB, leprosy and TB/HIV 
control manual, all individuals who had cough for two or more weeks were suspects for TB and will be diagnosed microscopically. Diagnosis takes two additional days before taking the result from laboratory. Therefore, a TB suspect is considered as promptly diagnosed and treated if it was done within three weeks [4].The difference in the duration of delay between recognizing TB symptoms by the patients to taking TB treatment in Mozambique and Nigeria will be because study participants recruited in Mozambique involved smear negative pulmonary TB patients. Definitive diagnosis of smear negative pulmonary TB is more difficult than smear positive counter parts, making the treatment initiation delayed for longer time [11]. Similarly, the reason for higher delay in Malawi will be because only new smear positive pulmonary TB patients were involved. As indicated in the current study delay for initiation of TB treatment was higher among new TB patients than retreatment smear positive pulmonary $\mathrm{TB}$ patients. Moreover, it is also different from studies conducted in other areas.

The median delay was lower than the estimate in India [9], Afghanistan [8], Kathmandu in Nepal [14], Brazil [10], Indonesia [16] and West Midland in England [17]. This difference emanates from only new smear positive pulmonary TB patients in Nepal, Brazil and Afghanistan partly. The other reason for the disagreement between Afghanistan's studies will be on the origin of TB patients involved (i.e almost all participants were from rural area where delay was significantly higher than the urban counter parts). Including extra pulmonary and other forms of TB will be the reason for the disagreement between the present study and that carried out in England and Indonesia.

Unacceptable delay for initiation of TB treatment was higher among residents in the rural area in south Ethiopia. About $85 \%$ of the Ethiopian people live in rural area. Similarly, majority of TB patients involved in this study were from the rural parts of south Ethiopia. In line with the findings of the present study, inquiries made by researchers in Afghanistan [8], Nigeria [13] and Indonesia [16] had found being resident in the rural area as risk factor for delayed initiation of treatment. The main reasons for this unacceptably longer duration before treatment might be due to geographical access to health service and cost of transportation to reach to the health facility in a longer distance from their residence [12]. In this study also low income of birr 450 or less per month is associated with increased delay for treatment of pulmonary TB. However, in migrant population in china, there is no association between longer delay for diagnosis and treatment and residence area. This might be due to improved income of citizens to cover transportation cost in china.

Most studies carried out indicate that female TB patients were more likely to delay for unacceptable length of time before taking treatment for their ailments. For example, in west midlands in England [17] and Malaysia [15], female TB patients delay for longer time. In the present study also large proportion of female patients delayed for longer time than proportion of males delayed though it is not significant. It also indicated that there is no difference in delay for initiation of treatment in different age categories but the highest delay was in the age group 35-54. In similar to the present study, previous two studies in Ethiopia [6, 7], Indonesia [16] west midlands in England [17] and in Mozambique [18] the time between onsets of TB symptoms and when treatment began did not differ in different age groups. However, as age increases, the total number of days elapsed before starting treatment for TB increases in Nigeria [13]. The disagreement between these differences might be related to the difference in the life expectancy in these study areas. Another important factor dealt was HIV infection status.

HIV increases the susceptibility of individuals for both infection and development of active disease. In this study HIV infected people were less likely to delay than HIV negative individuals though it is not statistically significant. In a systematic review carried out by Storla et al., 2008, $\mathrm{HIV}$ is the most important risk factor for unacceptably longer delay for initiation of treatment [11]. In contrast to this, HIV infection was the known protective factor for late initiation of treatment. For example, HIV decreases the time interval between onset TB symptoms to treatment in Mozambique [18] and Uganda [19]. This disagreement might be due to difference in the level of awareness about TB among HIV patients in different countries. This research was done with the following limitations.

One of the limitations of the current study emanates from the study design being cross-sectional as this hinders the ability to establish causal link between independent variables considered and unacceptable delay for initiation of TB treatment. The other limitation of this study is the risk of recall bias. The response of study participants about risk factors might not be always correct, (i.e. there is possibility of over or under reporting). In the current study we could not estimate the health facility and patient related delays and factors associated with these. Thus, the findings of the current study should be interpreted in light of the above limitations.

\section{Conclusion}

Large number of smear positive pulmonary TB patients delayed for more than the median delay before taking medications which render them non infectious after a few weeks. These infectious TB cases were transmitting the disease to their families and in the wider community making prevention and control difficult. Those living in the rural area and paid least amount of money per month suffer from TB long time and at the same time transmit the disease in the community. People living in the rural area of Ethiopia had poor geographical access to health facilities and difficulty of the cost of transportation. These calls for an improved access for diagnosis and treatment of TB in the rural community where about $85 \%$ of the Ethiopian population were living in order to be in track of the millennium development goal. 
Civil servants who earn the least salary per month had significant increment in the salary recently that will prevent their delay for initiation of treatment.

\section{Competing Interests}

We, authors declare that we have no competing interests.

\section{Authors' Contributions}

ZZ has contributed to the conception of the study question, designed the study, collected the data, analyzed the data, interpreted the data and drafted the manuscript. $\mathrm{ZM}$ is involved in conception and collecting the data. All the authors have read and approved the final version of this manuscript.

\section{Acknowledgment}

First, we would like to acknowledge Arba Minch University for its financial support. Our deep appreciation also goes to health care providers in TB clinics of Arba Minch Hospital, Chencha Hospital and Sawula Hospital. Lastly our gratitude to study participants would in the study.

\section{References}

[1] WHO. Global tuberculosis report 2013, Geneva-27, Switzerland, 2013

[2] WHO. The Global Tuberculosis Epidemic, Fact sheet.2010; available at www.kff.org.

[3] Federal ministry of health (MOH). Implementation Guideline for TB/HIV Collaborative Activities in Ethiopia, 2007: available at http://www.biomedcentral.com/1472$698 \mathrm{X} / 7 / 4$

[4] Ministry of health of Ethiopia (MoH). Tuberculosis leprosy and TB/HIV prevention and control program manual, addis abeba Ethiopia, $4^{\text {th }}$ edition, 2008.

[5] WHO. Global tuberculosis report 2012, Geneva, Switzerland, 2012.

[6] Belay M, Bjune G, Ameni G, Abebe F. Diagnostic and treatment delay among tuberculosis patients in Afar region, Ethiopia: a cross-sectional study, BMC public health. 2012; $12: 36$

[7] Hussen A, Biadgilign S, Tessema F, Mohammed S, Deribe $\mathrm{K}$, Deribew A. Treatment delay among pulmonary tuberculosis patients in pastoralist community in Bale Zone, south east Ethiopia, BMC research Notes. 2012; 5:320

[8] Sabawoon W, Sato H, Kobayashi Y. Delay in the treatment of pulmonary tuberculsosi: a report from Afganistan, Environ Health Prev Med. 2012; 17:53-61 DOI: 10.1007/s12199-011-0219-9.

[9] Konda SG, Melo CA, Giri PA, Behera AB. determinants of delay in diagnosis and treatment pulmonary tuberculosis in a new urban township in India: a cross-sectional study, international journal of medical science and public health.
2014; 3(2) DOI:105455/ijmsph.2013.011120131

[10] Maior ML, Guerra RL, Cailleaux-Cazar M, Golub JE, Conde MB.Time from symptom onset to the initiation of treatment of pulmonary tuberculosis in a city with a high incidence of the disease, Journal Bras Pneomol. 2012;38(2):202-209

[11] Storla DG, Yimer S, Bjune GA. A systematic review of delay in the diagnosis and treatment of tuberculosis, BMC public health. 2008; 8:15. DOI:10.1186/471-2458-8-15

[12] Tadesse T, Demissie M, Berhane Y, Kebede Y, Abebe M. Long distance travilling and financial burdens discourage tuberculosis DOTS treatment initiation and compliance in Ethiopia: a qualitative study, BMC public health. 2013; $13: 424$

[13] Ukwaja KN, Alobu I, Nweke CO, Onyenwe EC. Health-care seeking behavior, treatment delay and its determinants among pulmonary tuberculosis patients in rural Nigeria: a cross-sectional study, BMC health service research. 2013; $13: 25$.

[14] Bam T.S, Enarson D.A, Hinderaker S.G, Bam D.S. Longer delay in accessing treatment among current smokers with new sputum-smear positive tuberculosis in Nepal. International journal of tuberculosis and lung disease. 2012; $16(6): 822-827$

[15] Chang CT, Esterman A. Diagnostic delay among pulmonary tuberculosis patients in Sarawaka, Malaysia: a crosssectional study, rural and remote health. 2007; 7: 667

[16] Mahendradhata Y, Syahrizal BM, Utarini A. Delayed treatment of tuberculosis patients in rural areas of Yogyakarta Province, Indonesia, BMC public health. 2008; 8:393. DOI: $10.1186 / 1471-2458-8-393$.

[17] Sultan H, Haroon S, Syed N. Delay and completion of tuberculosis treatment: a cross-sectional study in the West Midlands, UK, journal of public health. 2008; 35(1):12-20 DOI: $10.1093 /$ pubmed/fds046

[18] Saifodine A, Gudo PS, Sidat M, Black J. Patient and health system delay among patients with pulmonary tuberculosis in Beira City, Mozambique, BMC public health. 2013; 13:559.

[19] Sendagire I, Loeff MV, Mubiru M, Konde-Lure J, Cobelens F. Long delay and missed opportunities in diagnosing smear-positive pulmonary tuberculosis in Kampala, Uganda: a cross sectional study, PLoS ONE. 2010; 5(12): e14459. Doi:10.1371/journal.pone.0014459.

[20] Bantubani N, Kabera G, Connolly C, Rustomjee R, Reddy T, Pym AS. High rate of potentially infectious tuberculosis and multidrug-resistant tuberculosis (MDR-TB) among hospital inpatients in KwaZulu Natal, south Africa indicate risk of nosocomial transmission, PLoS ONE. 2014; 9(3): e90868. Doi:10.1371/journal.pone.0090868

[21] Central Statistical Agency (CSA). (2007) Southern Peoples, Nations and Nationalities Region, 2007. URL: http://www.CSA.gov.et/index.php.

[22] Mfinaga SG, Mutayoba BK, Kahwa A, Kimaro G, Mtandu R, Ngodaya E, Egwaga S, Kitua AY. The magnitude and factors associated with delays and management of smear positive tuberculosis in Dar es Salaam, Tanzania, BMC Health Service Research. 2008; 8:158. DOI: 10.1186/14726963-8-158. 
[23] Kansiime C, Kiwuwa SM, Levi M, Asiimwe BB, Katamba A. Health service delay among pulmonary tuberculosis patients presenting to a national referral hospital, Kampala, Uganda: a cross-sectional study, PanAfrican Medical journal. 2013; 15:84. DOI: 10.11604/pamj.2013.15.84.2692.

[24] Li X, Jang S, Li X, Mei J, Zhang Q, Xu W, Li J, Li W, Liu HZ, Wang L. Predictors on delay of initial health-seeking in new pulmonary tuberculosis cases among migrant population in East China, PLoS ONE. 2012; 7(2): e311995. Doi:10.1371/journal.pone.00311995
[25] Zhou C, Tobe R.G, Chu J, Gen H, Wang X, Xu L. 2012. Detection delay of pulmonary tuberculosis patients among migrants in china: a cross-sectional study. International journal of tuberculosis and lung disease. 2012; 16(12):16301636

[26] Makwakwa L, Sheu M, Chiang C, Lin S, Chang PW. Patient and health system delay in the diagnosis and treatment of new and retreatment pulmonary tuberculosis cases in Malawi, BMC in factious diseases. 2014; 14:13 